\title{
Effect of Accelerated Aging Rate on the Capture of Fuel-Borne Metal Impurities by Emissions Control Devices
}

\author{
Aaron Williams and Robert McCormick \\ National Renewable Energy Laboratory \\ Michael Lance, Chao Xie, and Todd Toops \\ Oak Ridge National Laboratory \\ Rasto Brezny \\ Manufacturers of Emission Controls Assoc
}

\begin{abstract}
Small impurities in the fuel can have a significant impact on the emissions control system performance over the lifetime of the vehicle. Of particular interest in recent studies has been the impact of sodium, potassium, and calcium that can be introduced either through fuel constituents, such as biodiesel, or as lubricant additives. In a collaboration between the National Renewable Energy Laboratory and the Oak Ridge National Laboratory, a series of accelerated aging studies have been performed to understand the potential impact of these metals on the emissions control system. This paper explores the effect of the rate of accelerated aging on the capture of fuel-borne metal impurities in the emission control devices and the subsequent impact on performance. Aging was accelerated by doping the fuel with high levels of the metals of interest. Three separate evaluations were performed, each with a different rate of accelerated aging. The aged emissions control systems were evaluated through vehicle testing and then dissected for a more complete analysis of the devices. Results from these experiments show that increasing the rate of acceleration impacts the amount of fuel-borne metals that are captured by the catalyst, which subsequently impacts the catalyst performance. Beyond a certain threshold, the acceleration rate creates an artificial mechanism for catalyst deactivation. In the range of acceleration rates that were examined in this study, these effects were primarily isolated to the inlet of the catalyst whereas performance further down the length of the catalyst was mostly unaffected.
\end{abstract}

CITATION: Williams, A., McCormick, R., Lance, M., Xie, C. et al., "Effect of Accelerated Aging Rate on the Capture of FuelBorne Metal Impurities by Emissions Control Devices," SAE Int. J. Fuels Lubr. 7(2):2014, doi:10.4271/2014-01-1500.

\section{INTRODUCTION}

Metallic fuel contaminants such as sodium $(\mathrm{Na})$, potassium $(\mathrm{K})$, calcium ( $\mathrm{Ca}$ ) and magnesium (Mg) may be introduced into diesel fuel through a number of different sources. As one example, biodiesel production relies on sodium hydroxide or potassium hydroxide to catalyze the reaction of vegetable oils with methanol to form methyl esters. In this process, residual amounts of $\mathrm{Na}$ or $\mathrm{K}$ can be left behind. In addition, small amounts of $\mathrm{Ca}$ or $\mathrm{Mg}$ can be added to the fuel from the purification process $[1,2]$. These metal contaminants are converted to oxides, sulfates, hydroxides, or carbonates in the combustion process and form an inorganic ash that can be deposited onto the exhaust emission control devices. Alkali metals are well known poisons for catalysts and have been shown to negatively impact the mechanical properties of ceramic substrates $[\underline{3}, \underline{4}]$. Furthermore, alkali metal hydroxides such as sodium and potassium are volatilized in the presence of steam and can therefore penetrate the catalyst washcoat or substrate.

The research described in this paper was motivated by previous work investigating the impact of these fuel-borne metal impurities on the full-useful-life durability of exhaust catalysts. In the previous study, an accelerated method was developed to expose catalysts to full-useful-life exposure levels of $\mathrm{Na}, \mathrm{K}$, and Ca coming from a biodiesel containing metals at the specification limit [5]. The ASTM International standard for biodiesel (ASTM D6751) currently limits 100\% biodiesel (B100) to 5 parts per million (ppm) of $\mathrm{Na}+\mathrm{K}$ and $5 \mathrm{ppm}$ of $\mathrm{Ca}+\mathrm{Mg}$ (effectively limiting B20 to $1 \mathrm{ppm} \mathrm{Na+K}$ and $1 \mathrm{ppm} \mathrm{Ca+Mg).} \mathrm{To}$ accelerate exposure to these metals, a test fuel was doped with higher quantities of metal than normally allowable. The 150,000- 
mile full-useful-life requirement of a Ford F250 pickup was simulated in 100 hours by doping a B20 with $14 \mathrm{ppm}$ of $\mathrm{K}$. This represented a $14 x$ rate of acceleration for metal exposure. The results of this work raised questions about the impact of methods used for accelerated aging.

To investigate how the rate of accelerated aging impacts the catalyst, two additional experiments were run: 50 hours with B20 containing 28 ppm K and 200 hours with B20 containing 7 ppm $\mathrm{K}$. In total this generated three systems aged at three different rates of acceleration; however, each system was exposed to the same total amount of fuel-borne $\mathrm{K}$. The results of this research will help build upon the understanding of proper methods used for accelerated aging of exhaust emission control catalysts. This knowledge is not only important in guiding future studies to investigate the impact of biodiesel metal impurities, but may have broader application to studies looking at lubricant derived ash as well.

\section{TEST METHODS}

\section{Catalyst Aging}

The exhaust catalysts selected for accelerated aging studies were from a production 2011 Ford F250 pickup equipped with a 6.7L diesel engine. These systems included a diesel oxidation catalyst (DOC), selective catalyst reduction (SCR), and a diesel particulate filter (DPF). The DOC consisted of two separate monoliths mounted in series with a total volume of $4.35 \mathrm{~L}$. The SCR system included a pair of copper/zeolite catalysts mounted in series with a total volume of $9.88 \mathrm{~L}$. The DPF was a catalyzed $\mathrm{SiC}$ substrate and had a total volume of $8.2 \mathrm{~L}$. Further catalyst details are listed in Table 1. Three OEM exhaust systems were purchased from a local dealership to be used for accelerated aging. Each system was instrumented for temperature and pressure measurements and for exhaust sampling. These systems, as purchased from the dealership, were welded from end to end with no access to the individual catalyst components. Therefore, the DPF section was cut and flanged from the rest of the exhaust to allow for weighing the DPF to quantify ash loading. A schematic of the exhaust system is shown in Figure 1.

Table 1. Catalyst specification

\begin{tabular}{|l|l|l|l|}
\hline $\begin{array}{l}\text { Test } \\
\text { Piece }\end{array}$ & $\begin{array}{l}\mathrm{D} \times \mathrm{L} \\
\text { (in) }\end{array}$ & CPSI$^{*}$ & Coating \\
\hline DOC \#1 & $6.5 \times 3.25$ & 400 & Pd rich \\
\hline DOC \#2 & $6.5 \times 4.75$ & 400 & Pd rich \\
\hline SCR \#1 & $8 \times 6$ & 400 & Cu-Cha** \\
\hline SCR \#2 & $8 \times 6$ & 400 & Cu-Cha \\
\hline CDPF & $8 \times 10$ & 200 & Pt:Pd \\
\hline
\end{tabular}

*cells per square inch

Cu-Cha = copper-chabazite

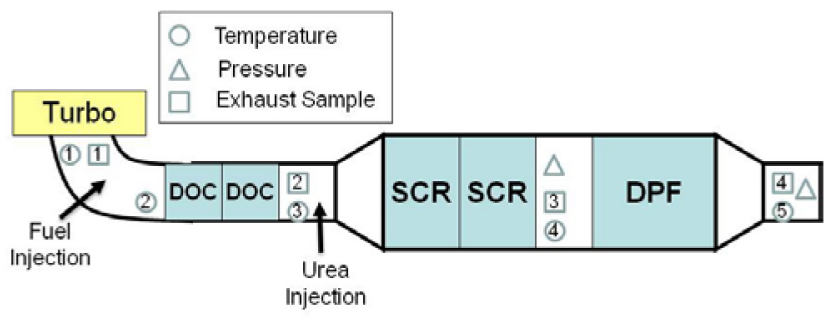

Figure 1. Schematic of exhaust system

For accelerated aging, these full exhaust systems were placed onto an accelerated aging platform, which was described in earlier studies $[\underline{5}, \underline{6}]$. The accelerated aging platform consisted of a Caterpillar 2008 C9 ACERT engine. This is an 8.8L, 300hp engine calibrated to meet the Tier III off-road emissions limit. The engine is turbocharged and direct injected and does not use an exhaust catalyst in its base configuration. By retrofitting the engine with exhaust emission controls, it served as a platform for exposing various catalysts and filters to exhaust gas from fuels containing metal impurities. The exhaust was retrofitted with a fuel injector placed $10 \mathrm{~cm}$ downstream of the turbo flange and $183 \mathrm{~cm}$ upstream of a diesel oxidation catalyst. This fuel injector was used to inject fuel that burned over the DOC, creating hot exhaust temperatures typical of a DPF regeneration event.

A three-mode test cycle was developed for the Caterpillar engine to achieve catalyst temperature and space velocity conditions consistent with operating parameters in an F250 pickup. The conditions for these three modes are shown in Table 2. This range of space velocities and temperatures was chosen based on data from the F250 pickup operating over the Federal Test Procedure (FTP) and US06 drive cycles on a chassis dynamometer. As the rate of accelerated aging was increased, the ratios of time among modes 1,2 , and 3 were adjusted. This was done to achieve the same amount of total time at the high-temperature condition experienced in mode 3 .

Table 2. Catalyst aging conditions

\begin{tabular}{|l|l|l|l|}
\hline Engine Mode & $\begin{array}{l}\text { Time } \\
(\mathrm{min})\end{array}$ & $\begin{array}{l}\text { SCR SV } \\
(1 / \mathrm{hr})\end{array}$ & $\begin{array}{l}\mathrm{SCR} \text { inlet } \\
\mathrm{T}\left({ }^{\circ} \mathrm{C}\right)\end{array}$ \\
\hline $\begin{array}{l}1 \text { (low-temp } \\
\text { operation) }\end{array}$ & 15 & $20 \mathrm{k}$ & 200 \\
\hline $\begin{array}{l}2 \text { (high-temp } \\
\text { operation) }\end{array}$ & 15 & $57 \mathrm{k}$ & 340 \\
\hline $\begin{array}{l}3 \text { (regen } \\
\text { operation) }\end{array}$ & 30 & $57 \mathrm{k}$ & 700 \\
\hline
\end{tabular}

The B20 test fuels were made from a petroleum-based ultra-low sulfur diesel and a soy-based biodiesel, neither of which contained any measureable quantity of $\mathrm{K}$ at a detection limit of 1 $\mathrm{ppm}$. Batches of B20 were blended in 250-gallon tote quantities and then doped with potassium dodecylbenzene sulfonate to achieve precisely controlled levels of K. Once the B20 batches were blended and doped, they were allowed to mix overnight 
with a paddle wheel agitator. A sample was then collected for analysis. Samples were collected from the top and bottom of the tote to ensure a homogeneous mixture of the dopant.

Fuel dopant levels were selected to simulate full-useful-life metal exposure coming from B20 at three different rates of accelerated aging: $7 \mathrm{x}, 14 \mathrm{x}$, and $28 \mathrm{x}$. As the $\mathrm{K}$ dopant level was increased, the duration of engine operation was reduced such that the total exposure to $\mathrm{K}$ would be identical in all three tests. These levels and durations of testing were chosen to achieve 150,000 miles worth of metal exposure, assuming normal vehicle operation with a B20 blended from B100 at the ASTM specification limit of $5 \mathrm{ppm} \mathrm{K}$. This corresponds to a B20 fuel containing $1 \mathrm{ppm}$ of the impurity. The three different aging scenarios are detailed in Table 3.

Table 3. Rates of accelerated aging

\begin{tabular}{|l|l|l|}
\hline $\begin{array}{l}\text { Rate of Accelerated } \\
\text { Aging }\end{array}$ & $\begin{array}{l}\text { K dopant level in } \\
\text { B20 (ppm) }\end{array}$ & $\begin{array}{l}\text { Duration of } \\
\text { engine operation } \\
\text { (hours) }\end{array}$ \\
\hline $7 x$ & 7 & 200 \\
\hline $14 x$ & 14 & 100 \\
\hline $28 x$ & 28 & 50 \\
\hline
\end{tabular}

The catalysts were evaluated for signs of deactivation by installing the full exhaust system onto a Ford F250 pickup for emissions testing. This vehicle was certified to a Tier 2 Bin 8 emission limit of $0.2 \mathrm{~g} / \mathrm{mile}_{\mathrm{NO}}$. The vehicle was operated on a chassis dynamometer over the FTP cycle with emissions measurement following the U.S Environmental Protection Agency certification test methods. Prior to emissions testing, the catalysts went through a set of conditioning cycles to ensure that the catalysts were at the same state. This emissions testing was conducted with standard ultra-low sulfur diesel containing no measurable quantity of metals. Further details on procedures for emissions testing and catalyst pre-conditioning are described in Reference $\underline{5}$.

\section{Catalyst Post-Mortem}

At the completion of catalyst aging and vehicle emissions testing, the catalysts were cored and sectioned for detailed post mortem analysis. The exhaust system consisted of two DOC and two SCR monoliths mounted in series. Catalyst cores with approximately 1 inch diameter were taken down the length of each of these DOC and SCR bricks close to the radial center of each catalyst. Each catalyst core was then divided equally into four parts, as shown in Figures 2 and $\underline{3}$. From the inlet to outlet direction, the four parts were labeled as Inlet, Mid 1, Mid 2 , and Outlet, respectively.

The harvested samples were analyzed for $\mathrm{K}$ content in the catalyst washcoat by scanning electron microscope-energy dispersive X-ray analysis (SEM-EDAX). Washcoat powders were scraped from each sample and ground into a fine powder for SEM-EDAX analysis. The washcoat powders thus obtained were loaded onto carbon tapes, followed by carbon coating to minimize charging during elemental analysis. SEM-EDAX measurements were performed on a Hitachi S4800 FEG-SEM with an EDAX Genesis SDD-EDS detector. The operation voltage and current were $25 \mathrm{kV}$ and $20 \mu \mathrm{A}$, respectively. Elemental analyses were done at 2,000x magnification, corresponding to a sampled area of $48 \mu \mathrm{m}$ by $64 \mu \mathrm{m}$. For all samples, the elemental analyses were repeated three times through randomly measuring three different locations, and the results were averaged. The elemental weight percent was calculated using the fundamental parameters method without any standards, and the contribution from cordierite debris was subtracted from the final result.

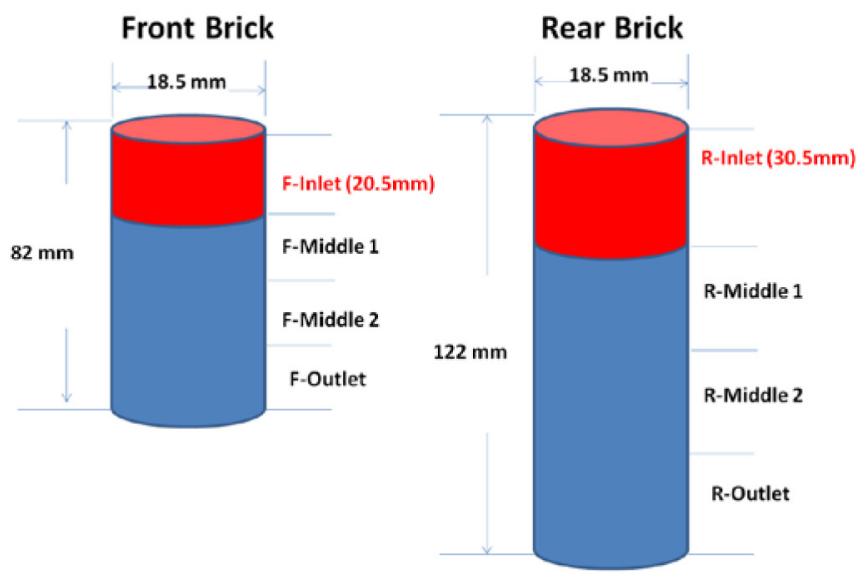

Figure 2. DOC Cores
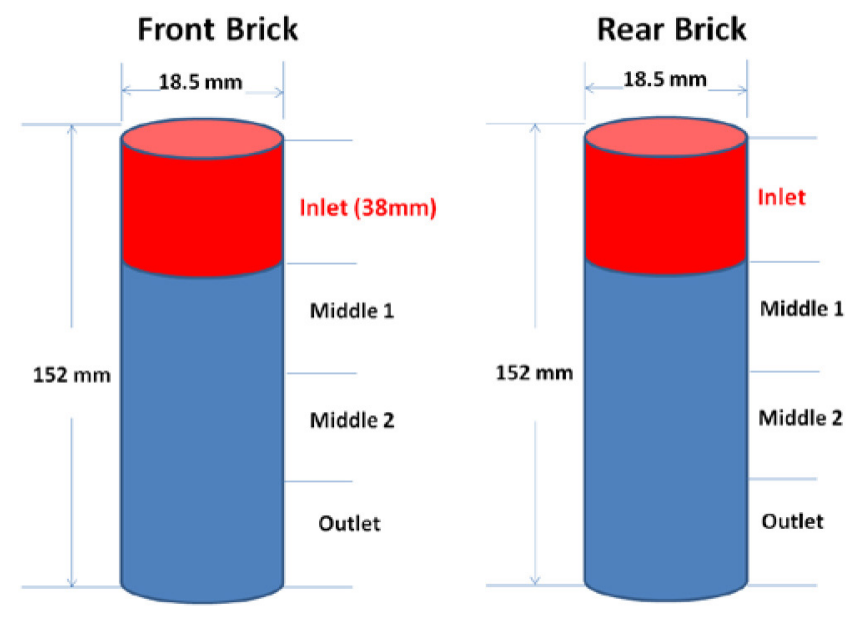

Figure 3. SCR Cores

Measurement of the carbon monoxide (CO), hydrocarbon $(\mathrm{HC})$ and nitrogen oxide (NO) oxidation activity of the DOC samples and the NO conversion of the SCR samples was conducted in a bench flow reactor. Conditions used in the bench flow reactor experiments are shown in Tables 4 and $\underline{5}$. The temperature of the catalyst sample was ramped from $100^{\circ} \mathrm{C}$ to $650^{\circ} \mathrm{C}$ at a rate of $10^{\circ} \mathrm{C} / \mathrm{min}$. 
Table 4. Bench flow reactor conditions for DOC evaluation

\begin{tabular}{|l|l|}
\hline Gas & Concentration \\
\hline $\mathrm{C}_{3} \mathrm{H}_{6}$ & $550 \mathrm{ppm}$ \\
\hline $\mathrm{CO}$ & $2,500 \mathrm{ppm}$ \\
\hline $\mathrm{NO}$ & $400 \mathrm{ppm}$ \\
\hline $\mathrm{O}_{2}$ & $10 \%$ \\
\hline $\mathrm{H}_{2} \mathrm{O}$ & $6 \%$ \\
\hline $\mathrm{CO}_{2}$ & $13 \%$ \\
\hline $\mathrm{N}_{2}$ & Balance \\
\hline Flow Rate & $4,892 \mathrm{~mL} / \mathrm{min}$ \\
\hline Space Velocity & $50,000\left(\mathrm{hr}^{-1}\right)$ \\
\hline
\end{tabular}

Table 5. Bench Flow Reactor Conditions for SCR Evaluation

\begin{tabular}{|l|l|}
\hline Gas & Concentration \\
\hline $\mathrm{NH}_{3}$ & $350 \mathrm{ppm}$ \\
\hline $\mathrm{NO}$ & $350 \mathrm{ppm}$ \\
\hline $\mathrm{O}_{2}$ & $14 \%$ \\
\hline $\mathrm{H}_{2} \mathrm{O}$ & $5 \%$ \\
\hline $\mathrm{CO}_{2}$ & $5 \%$ \\
\hline $\mathrm{N}_{2}$ & Balance \\
\hline Flow Rate & $5,441 \mathrm{~mL} / \mathrm{min}$ \\
\hline Space Velocity & $30,000\left(\mathrm{hr}^{-1}\right)$ \\
\hline
\end{tabular}

\section{RESULTS}

The accelerated aging experiments generated three exhaust systems, all exposed to the same total quantity of $\mathrm{K}$ but at different rates of exposure. Table 6 shows the aging conditions for each of the three systems and the resultant vehicle emission test results at different stages of the aging process. The table shows that while the three exhaust systems were aged for different durations, the total time at high temperatures were identical $\left(45\right.$ hours above $600^{\circ} \mathrm{C}$ ). Also note that the total exposure to $\mathrm{K}$ should be the same as the dopant level of the fuel was adjusted for each test. Thus, all three exhaust systems experienced the same amount of $\mathrm{K}$ exposure and thermal exposure but at different rates.

The $\mathrm{NO}_{\mathrm{x}}$ emission standard for the Ford pickup was $0.20 \mathrm{~g} /$ mile. As shown in Table 6, all three exhaust systems resulted in $\mathrm{NO}_{x}$ below this standard prior to accelerated aging. At the end of aging, the system aged at the fastest acceleration rate was above the $\mathrm{NO}_{x}$ standard, while the other two systems were still below the standards. It is worth noting, however, that measuring $\mathrm{NO}_{x}$ emissions at these low levels was challenging and highly dependent on the preconditioned state of the catalysts and vehicle. Prior to each emission test, the system was prepped to ensure that the catalysts were at the same state. The catalyst prep procedure consisted of (1) conducting a forced DPF regeneration event while driving the Highway Fuel Economy Test (HWFET) cycle, followed by (2) conducting two repeats of the LA4 test cycle, and finally, (3) a minimum 7-hour soak period. This system conditioning ensured that the vehicle did not initiate a DPF regeneration event during the FTP and that the SCR catalysts had the same opportunity for ammonia $\left(\mathrm{NH}_{3}\right)$ adsorption prior to the FTP emissions test. Even with these preconditioning procedures, we still saw high variability in these low $\mathrm{NO}_{x}$ levels. In the case of the two systems aged at $14 x$ and $28 x$ rate of acceleration, we saw that the mid-point emissions test had higher $\mathrm{NO}_{x}$ than the fully aged emissions test. Because of this variability we rely on more detailed post-mortem analysis of the aged parts to identify clear signs of deactivation. These results are described below.

Table 6. Aging Conditions and Vehicle Emission Results

\begin{tabular}{|c|c|c|c|}
\hline $\begin{array}{l}\text { Rate of } \\
\text { Accelerated } \\
\text { Aging }\end{array}$ & $28 x$ & $14 x$ & $7 x$ \\
\hline $\begin{array}{l}\text { B20 K content } \\
(\mathrm{ppm})\end{array}$ & 28 & 14 & 7 \\
\hline $\begin{array}{l}\text { Aging time } \\
\text { (hours) }\end{array}$ & 50 & 100 & 200 \\
\hline $\begin{array}{l}\text { Temp }>600^{\circ} \mathrm{C} \\
\text { (hours) }\end{array}$ & 45.0 & 45.1 & 45.0 \\
\hline $\begin{array}{l}\mathrm{NO}_{x} \text { pre-aging } \\
\text { (g/mile) }\end{array}$ & 0.17 & 0.19 & 0.10 \\
\hline $\begin{array}{l}\mathrm{NO}_{\times} \text {mid-aging } \\
(\mathrm{g} / \mathrm{mile})\end{array}$ & $0.33^{*}$ & $0.25^{*}$ & 0.17 \\
\hline $\begin{array}{l}\mathrm{NO}_{\times} \text {post-aging } \\
(\mathrm{g} / \mathrm{mile})\end{array}$ & $0.30^{*}$ & 0.12 & 0.20 \\
\hline
\end{tabular}

*above the $0.2 \mathrm{~g} / \mathrm{mile}$ EPA standard

Figure 4 shows the concentration of $\mathrm{K}$ that was measured in the washcoat of the aged DOCs. These data were collected by SEM-EDAX at eight separate locations down the length of the DOC. The relative location of each of these samples is illustrated in Figure 2. In the case of each aged sample, we see that the concentration of $\mathrm{K}$ is highest at the inlet to the DOC and decreases down the length of the catalyst. Also of note in Figure 4 is that the rate of accelerated aging has a large impact on the $\mathrm{K}$ concentration in the DOC washcoat. This is most pronounced at the inlet positions where the $\mathrm{K}$ concentration increases from $1.5 \%$ to $2.9 \%$ to $8.7 \%$ as the rate of accelerated aging is increased from a factor of $7 x$ to $14 x$ to $28 x$, respectively.

Figures $5, \underline{6}, \underline{7}$ show the relative change in catalytic activity for each of these aged DOCs. Figure 5 shows the light-off temperature for $90 \%$ conversion (T90) for $\left(\mathrm{C}_{3} \mathrm{H}_{6}\right)$. These data illustrate the impact that rate of accelerated aging has on the catalyst deactivation. The light-off temperature for the inlet of the most rapidly aged catalyst was $77^{\circ} \mathrm{C}$ higher than the least rapidly aged catalyst. This is consistent with the nearly 6 -fold increase in $\mathrm{K}$ found in the washcoat of this catalyst. The 
light-off for the catalyst aged at a $14 x$ rate of acceleration is only $8^{\circ} \mathrm{C}$ higher than that of the catalyst aged at a $7 x$ rate of acceleration. Also note that the impact of accelerated aging rate on $\mathrm{HC}$ light-off was isolated to the inlet of the catalyst, with no differences seen at the outlet of the DOCs. Studies by Li et al. of field-aged DOCs also show this non-uniform aging along the axial length of the catalyst []].

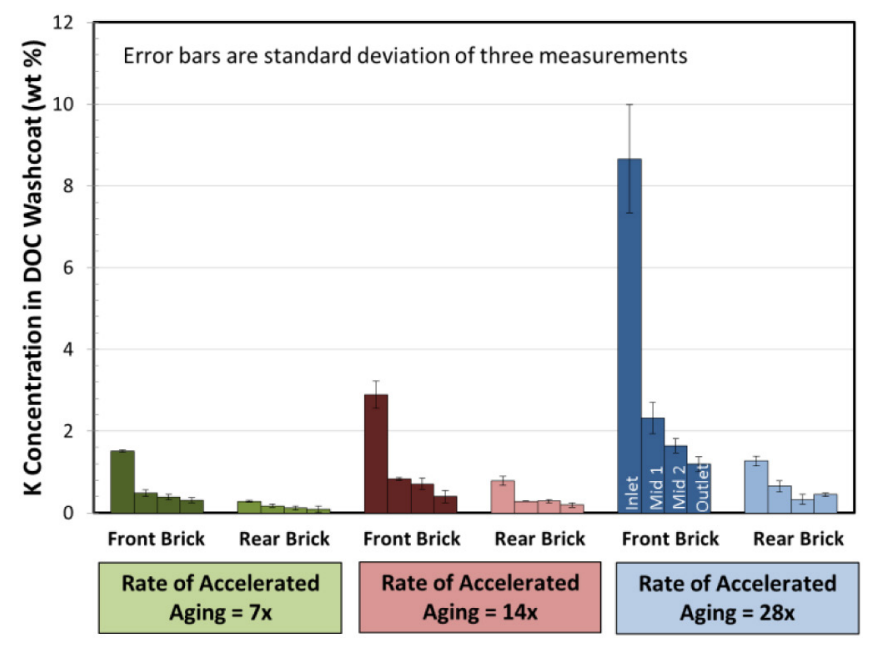

Figure 4. K concentration in aged DOC samples

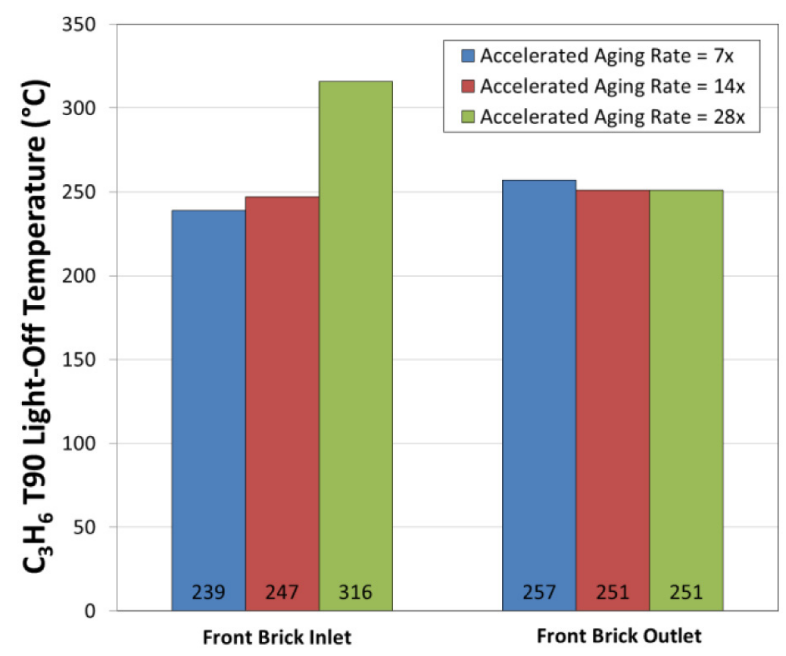

Figure 5. Temperature for $90 \%$ conversion (T90): HC light-off of aged DOC samples

Figure 6 shows the T90 light-off temperatures for CO. These data show a similar trend in performance with the most rapidly aged catalyst having a $79^{\circ} \mathrm{C}$ higher light-off temperature than the least rapidly aged catalyst. As with the $\mathrm{HC}$ light-off performance, the change in performance between the catalyst aged at a $14 x$ rate of acceleration and a $7 x$ rate of acceleration was minimal. There was also little impact of accelerated aging rate on the performance at the outlet of the DOCs. While the rate of accelerated aging did impact the T90 light-off temperatures for $\mathrm{CO}$ and $\mathrm{HC}$, the peak conversion was always $100 \%$ for the DOC.

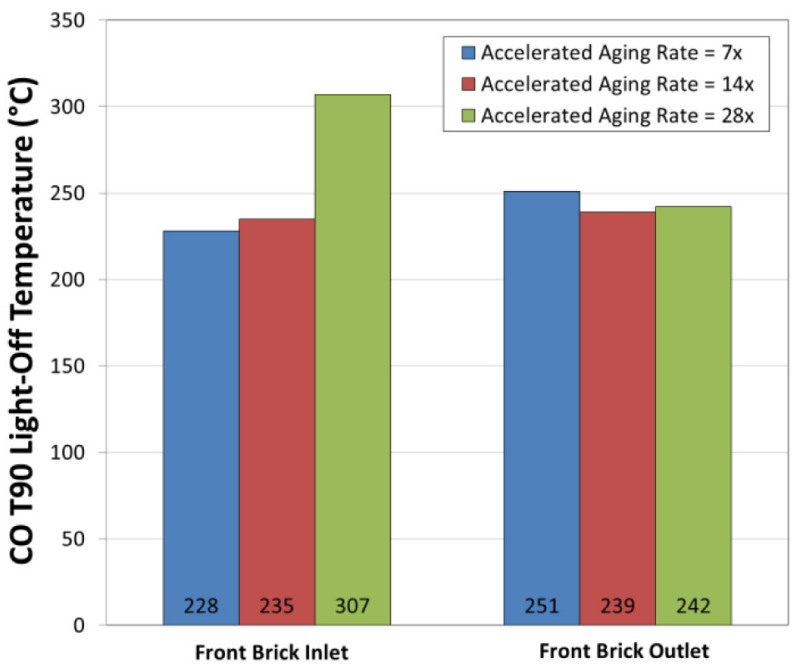

Figure 6. Temperature for $90 \%$ conversion (T90): CO light-off of aged DOC samples

Figure 7 illustrates the performance for NO oxidation of the aged catalysts. This figure shows the temperature at which $20 \%$ of the total $\mathrm{NO}_{x}$ is $\mathrm{NO}_{2}$. Compared to the $\mathrm{HC}$ and $\mathrm{CO}$ light-off, NO oxidation appears to be the most sensitive to the rate of accelerated aging. T20 for the most rapidly aged catalyst was $140^{\circ} \mathrm{C}$ higher than T20 of the least rapidly aged catalyst. Unlike the $\mathrm{HC}$ and $\mathrm{CO}$ light-off performance, the catalyst aged at a $14 \mathrm{x}$ rate of acceleration is even different than the catalyst aged at a $7 x$ rate of acceleration. Again, this impact of accelerated aging rate is primarily isolated to the inlet of the front catalyst with the outlet performance being very similar.

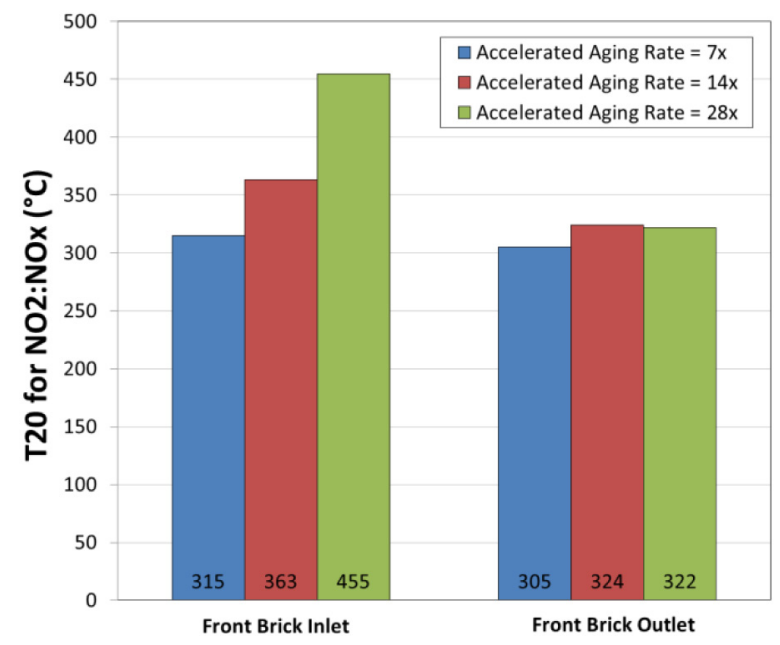

Figure 7. Temperature for 20\% conversion (T20): NO light-off of aged DOC samples

Figure 8 shows the concentrations of $\mathrm{K}$ that were measured in the washcoat of the aged SCR catalysts. These data were collected by SEM-EDAX at eight separate locations down the length of the catalyst. The relative locations of each of these samples are illustrated in Figure 3 . In comparing Figure 8 to Figure 4, one can see that there is significantly more $\mathrm{K}$ captured by the DOC than the SCR. For example, the inlet to the DOC aged at $28 \mathrm{x}$ acceleration rate contained $8.6 \% \mathrm{~K}$ while 
the corresponding SCR sample only contained $0.8 \% \mathrm{~K}$. As was the case for the DOC, the concentration of $\mathrm{K}$ is highest at the inlet to the SCR and decreases further down the length of the catalyst. As was also seen with the DOC, the rate of accelerated aging impacted the amount of $\mathrm{K}$ that was captured by the SCR. The K concentration measured at the inlet of the front SCR catalyst increased from $0.5 \%$ to $0.6 \%$ to $0.8 \%$ as the rate of accelerated aging is increased from a factor of $7 x$ to $14 x$ to $28 \mathrm{x}$, respectively. The $\mathrm{K}$ concentration in the washcoat was also measured for an un-aged SCR catalyst. It was found to be approximately $0.2 \%$.

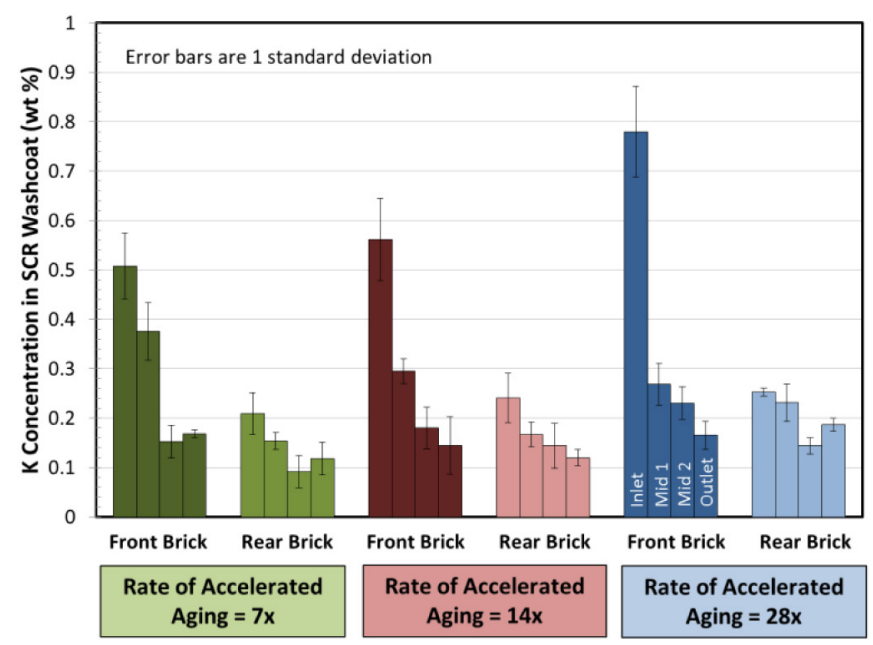

Figure 8. K content in aged SCR samples

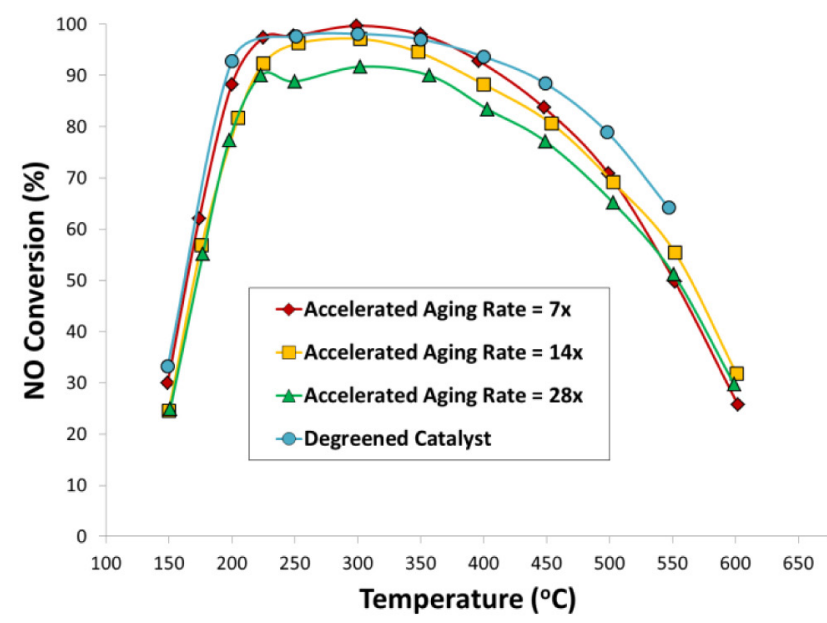

Figure 9. $\mathrm{NO}_{\mathrm{x}}$ conversion for aged front brick inlet SCR samples

Figure 9 illustrates the emissions performance for these SCR catalysts aged at the different rates of acceleration. This plot shows the percent $\mathrm{NO}$ conversion measured in a bench flow reactor over a range of temperatures. This performance was measured for the inlet of the front SCR catalyst. As seen in the plot, the un-aged catalyst and the catalyst aged at a $7 x$ rate of acceleration have similar performance. The catalyst aged at a $14 \mathrm{x}$ rate of acceleration has similar performance above about $250^{\circ} \mathrm{C}$, but slightly reduced performance below $250^{\circ} \mathrm{C}$. The catalyst aged at a $28 \mathrm{x}$ rate of acceleration has decreased performance throughout the entire temperature range.
Illustrating the impact on low temperature operation, the NO conversion for $200^{\circ} \mathrm{C}$ drops from $88 \%$, to $82 \%$, to $77 \%$ as the rate of accelerated aging was increased from $7 x$, to $14 x$, to $28 x$, respectively.

The SEM-EDAX results allowed us to quantify the total amount of $\mathrm{K}$ captured by the DOC and SCR in the engine aging process. The following equation was used to estimate the total amount of $\mathrm{K}$ in the DOC and SCR bricks:

$$
\begin{aligned}
& \text { Weight of } K \text { in catalysts } \\
& \quad=\text { Weight of catalyst washcoat } \\
& \times \text { Weight percent of } K \text { in washcoat }
\end{aligned}
$$

From this, the K capture efficiency for the DOC and SCR was calculated based on following equation:

$$
K \text { capture efficiency }(\%)=\frac{\text { Weight of } K \text { in washcoat }}{\text { Total weight of } K \text { in burned fuel }}
$$

The total ash collected by the DPF was measured by weighing the filter at the beginning and ending of accelerated aging. This total ash collected by the DPF would include K-ash from the fuel, as well as lube oil derived ash products. By using data from a previous study conducted with ULSD []ㅡ we make an estimation for the amount of lube oil derived ash. This allows us to then estimate the total weight of K-ash on the DPF with the following equation:

$$
\begin{aligned}
\text { Weight of } K \text { ash } & =\text { Weight of ash upon B20 aging } \\
& - \text { Weight of ash upon ULSD aging }
\end{aligned}
$$

Assuming that the $\mathrm{K}$ ash in the DPF was $\mathrm{K}_{2} \mathrm{SO}$, we calculate the total amount of $\mathrm{K}$ collected by the DPF. Table 7 summarizes the $\mathrm{K}$ captured by each exhaust component, as a percentage of the total $\mathrm{K}$ burned in the engine. These estimates indicate that the total $\mathrm{K}$ capture efficiency for the full system (DOC + SCR + DPF) was $79.2 \%, 53.1 \%$, and $49.8 \%$ for accelerated $\mathrm{K}$ aging rate of $7 x, 14 x$, and $28 x$, respectively.

Table 7. Percentage of K Captured by Each Exhaust Component

\begin{tabular}{|l|c|c|c|}
\hline & $7 x$ & $14 x$ & $28 x$ \\
\hline DOC & $1.1 \%$ & $2.2 \%$ & $5.4 \%$ \\
\hline SCR & $0.3 \%$ & $0.3 \%$ & $0.4 \%$ \\
\hline DPF & $77.8 \%$ & $50.6 \%$ & $44.0 \%$ \\
\hline Total & $79.2 \%$ & $53.1 \%$ & $49.8 \%$ \\
\hline
\end{tabular}

\section{DISCUSSION}

The results from this study showed that the rate of accelerated aging does impact the amount of $\mathrm{K}$ captured by the catalysts. This increased level of $\mathrm{K}$ in the catalyst correlated with reduced performance for $\mathrm{CO}, \mathrm{HC}$, and $\mathrm{NO}$ oxidation of the DOC, as well as $\mathrm{NO}_{x}$ conversion across the SCR. These changes in $\mathrm{K}$ capture and subsequent performance were primarily isolated to the inlet of the first catalyst brick. And, in general, the $\mathrm{K}$ capture was very similar for the catalysts aged at a $7 x$ and a $14 x$ rate of acceleration. However, the most rapidly aged catalysts (28x) had significantly higher levels of $\mathrm{K}$ and reduced performance. 
These results indicate that the rate of accelerated aging beyond a certain threshold creates an artificial level of deterioration in catalyst performance.

With these ideas in mind, further characterization of the DOC was conducted. Figure 10 shows images taken from the DOCs with an optical microscope. These images show a 5-mm length at the inlet of the DOCs. As seen in Figure 10(b), a glaze was found coating the inlet of the most rapidly aged DOC. This material was analyzed by Raman spectroscopy and was discovered to be potassium sulfate $\left(\mathrm{K}_{2} \mathrm{SO}_{4}\right)$. This glaze was not seen in the inlet to the least rapidly aged DOC. It is possible that when too rapid an acceleration rate is used for catalyst aging, a different mechanism of deactivation begins to take place, which could be related to the formation of this $\mathrm{K}_{2} \mathrm{SO}_{4}$ glaze.
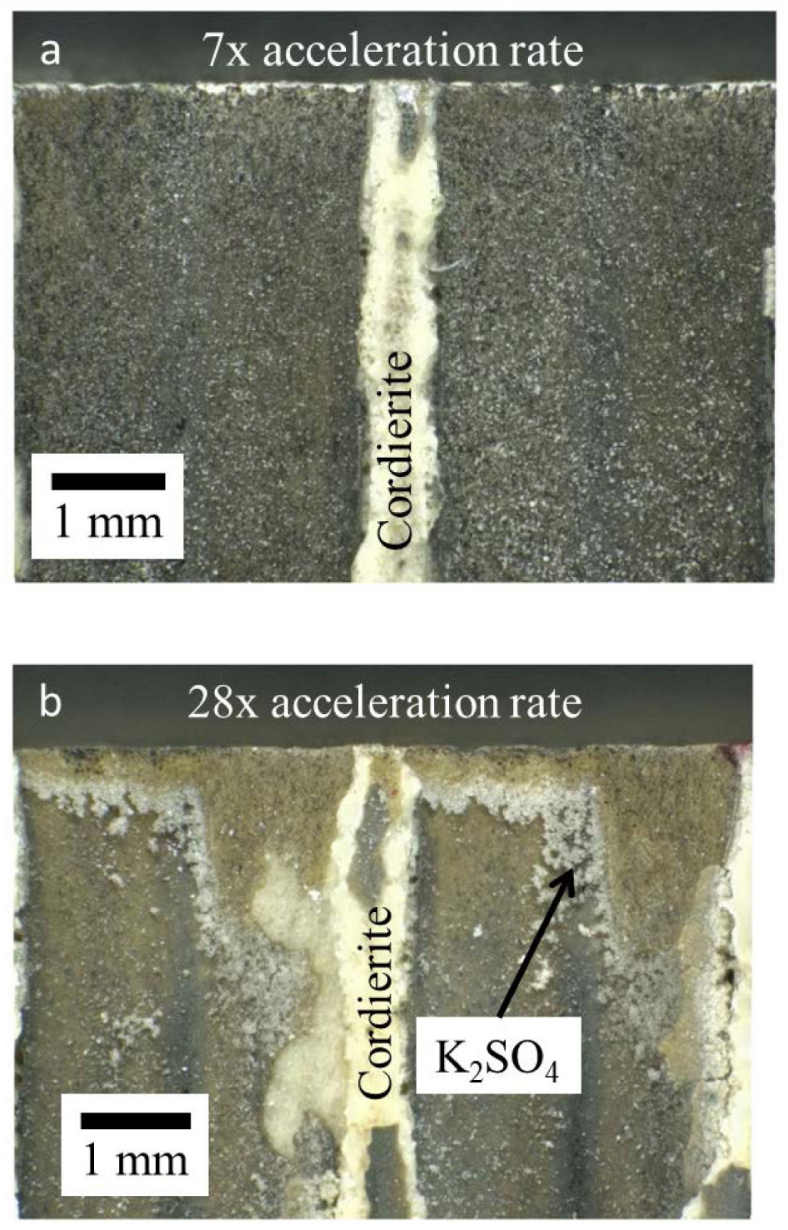

Figure 10. Microscope images of least rapidly aged DOC (a) and most rapidly aged DOC (b)

One possible explanation for the changes in capture rate of $\mathrm{K}$ relates to the form of the $\mathrm{K}$ after combustion. Depending on exhaust temperatures and chemistry, the $\mathrm{K}$ may form hydroxide, sulfate, or nitrate ash. Recall that the rate of accelerated aging was adjusted by increasing the level of $\mathrm{K}$ in the fuel. When the fuel was doped to higher levels of $K$, the ratio of $\mathrm{K}$ to sulfur (S) in the fuel changed. To further complicate matters, the dopant also contains $S$, so this needs to be accounted for as well. Table 8 lists the $\mathrm{K}: \mathrm{S}$ ratios found in the fuel for each case in this study. This change in the K:S ratio could result in changes to the form of $\mathrm{K}$ ash in the exhaust. Further work is ongoing to determine how this change in the $\mathrm{K}: \mathrm{S}$ ratio may be related to the formation of the $\mathrm{K}_{2} \mathrm{SO}_{4}$ glaze found on the DOC.

Table 8. Ratios of K:S found in the fuel

\begin{tabular}{|l|l|l|}
\hline & $\begin{array}{l}\text { K:S } \\
\text { (Weight ratio) }\end{array}$ & $\begin{array}{l}\text { K:S } \\
\text { (Molar ratio) }\end{array}$ \\
\hline $7 x$ & 0.60 & 0.49 \\
\hline $14 x$ & 0.80 & 0.66 \\
\hline $28 x$ & 0.97 & 1.26 \\
\hline
\end{tabular}

\section{CONCLUSIONS}

The present work was undertaken to elucidate how the acceleration rate of catalyst aging impacts the amount of fuel-borne metals that are captured by the catalysts and their subsequent performance in engine emissions control. These results can be used to guide the design of experiments in future accelerated catalyst aging studies. A set of catalysts were exposed to the same total amount of $\mathrm{K}$ but with varying acceleration factors. SEM-EDAX was employed to investigate the impact of the acceleration rate on the distribution of $K$ in the aged catalysts. It was found that the $\mathrm{K}$ concentrations in aged DOC and SCR samples progressively decreased along the catalysts from inlet to outlet. Interestingly, in spite of same total amount of $\mathrm{K}$ exposure, the most rapidly aged catalysts exhibited elevated $\mathrm{K}$ concentrations. We proposed that the observed impact may be related to the varying $\mathrm{K}: \mathrm{S}$ ratios in the fuel, which could impact the final form of $\mathrm{K}$ ash in the exhaust. Future work will investigate if this change in fuel chemistry could be related to a $\mathrm{K}_{2} \mathrm{SO}_{4}$ glaze seen on the inlet of the most rapidly aged DOC.

\section{REFERENCES}

1. Alleman, T.L., and McCormick, R.L., "Results of the 2007 B100 Quality Survey," National Renewable Energy Laboratory, Golden, CO, NREL/TP-540-42787, March 2008.

2. Alleman, T.L., Fouts, L., and Chupka, G.M., "Quality Parameters and Chemical Analysis for Biodiesel Produced in the United States in 2011," National Renewable Energy Laboratory, Golden, CO, NREL/TP-5400-57662, March 2013.

3. Dou, D. and Balland, J., "Impact of Alkali Metals on the Performance and Mechanical Properties of NOx Adsorber Catalysts," SAE Technical Paper 2002-01-0734, 2002, doi:10.4271/2002-01-0734.

4. Cavataio, G., Jen, H., Dobson, D., and Warner, J., "Laboratory Study to Determine Impact of $\mathrm{Na}$ and $\mathrm{K}$ Exposure on the Durability of DOC and SCR Catalyst Formulations," SAE Technical Paper 2009-01-2823, 2009, doi:10.4271/2009-01-2823.

5. Williams, A., Burton, J., McCormick, R., Toops, T.et al., "Impact of Fuel Metal Impurities on the Durability of a Light-Duty Diesel Aftertreatment System," SAE Technical Paper 2013-01-0513, 2013, doi:10.4271/2013-01-0513. 
6. Williams, A., McCormick, R., Luecke, J., Brezny, R.et al., "Impact of Biodiesel Impurities on the Performance and Durability of DOC, DPF and SCR Technologies," SAE Int. J. Fuels Lubr. 4(1):110-124, 2011, doi:10.4271/2011-01-1136.

7. Li, J., Szailer, T., Watts, A., Currier, N.et al., "Investigation of the Impact of Real-World Aging on Diesel Oxidation Catalysts," SAE Int. J. Engines 5(3):985-994, 2012, doi:10.4271/2012-01-1094.

\section{CONTACT INFORMATION}

Aaron Williams

National Renewable Energy Lab

15013 Denver West Parkway

Golden, CO 80401

(303) 275-3153

aaron.williams@nrel.gov

Todd J. Toops

Oak Ridge National Laboratory

P.O. Box 2008

Oak Ridge, TN 37831

(865) 946-1207

toopstj@ornl.gov

\section{ACKNOWLEDGMENTS}

Support from the National Biodiesel Board, the United Soybean Board, and the U.S. Department of Energy, Office of Vehicle Technologies (Fuels Technologies Program and Propulsion Materials Programs) is gratefully acknowledged. The authors would like to acknowledge the support of Roger Gault of the Truck and Engine Manufacturers Association, and an industry technical steering committee comprised of engine and emission control experts for their technical input used in developing the accelerated durability test protocol. We would also like to acknowledge the contributions of Shirley Waters in the collection of the CTE data.

\section{DEFINITIONS/ABBREVIATIONS}

$\mathrm{Ca}$ - calcium

CO - carbon monoxide

DOC - diesel oxidation catalyst

DPF - diesel particulate filter

FTP - Federal Test Procedure

HC - hydrocarbons

HWFET - Highway Fuel Economy Test

$\mathbf{K}$ - potassium

Mg - magnesium

$\mathrm{Na}$ - sodium

$\mathrm{NO}_{\mathbf{x}}$ - oxides of nitrogen

S - sulfur

SCR - selective catalyst reduction

SEM-EDAX - scanning electron microscope- energy dispersive $\mathrm{X}$-ray analysis 


\section{APPENDIX}

Table A.1. Weight \% of K Concentrations measured in the DOC

\begin{tabular}{|l|l|l|l|l|l|l|l|l|}
\hline & \multicolumn{3}{|c|}{ Front Brick } & & \multicolumn{3}{c|}{ Rear Brick } \\
\hline Position & inlet & mid 1 & mid 2 & outlet & inlet & mid 1 & mid 2 \\
\hline $\begin{array}{l}7 \times \text { acceleration } \\
\text { rate }\end{array}$ & 1.509 & 0.483 & 0.382 & 0.303 & 0.283 & 0.172 & 0.118 \\
\hline $\begin{array}{l}14 x \\
\text { acceleration } \\
\text { rate }\end{array}$ & 2.893 & 0.830 & 0.710 & 0.397 & 0.786 & 0.284 & 0.087 \\
\hline $\begin{array}{l}28 x \\
\text { acceleration } \\
\text { rate }\end{array}$ & 8.664 & 2.319 & 1.641 & 1.190 & 1.269 & 0.651 & 0.291 \\
\hline
\end{tabular}

Table A.2. Weight $\%$ of $\mathrm{K}$ Concentrations measured in the SCR

\begin{tabular}{|l|l|l|l|l|l|l|l|l|}
\hline & \multicolumn{3}{|c|}{ Front Brick } & \multicolumn{5}{c|}{ Rear Brick } \\
\hline Position & inlet & mid 1 & mid 2 & outlet & inlet & mid 1 & mid 2 \\
\hline $\begin{array}{l}7 \times \text { acceleration } \\
\text { rate }\end{array}$ & 0.508 & 0.376 & 0.153 & 0.168 & 0.209 & 0.154 & 0.092 \\
\hline $\begin{array}{l}14 x \\
\text { acceleration } \\
\text { rate }\end{array}$ & 0.562 & 0.295 & 0.180 & 0.145 & 0.241 & 0.167 & 0.118 \\
\hline $\begin{array}{l}28 \mathrm{x} \\
\text { acceleration } \\
\text { rate }\end{array}$ & 0.780 & 0.269 & 0.230 & 0.165 & 0.253 & 0.231 & 0.144 \\
\hline
\end{tabular}

This is a work of a Government and is not subject to copyright protection. Foreign copyrights may apply. The Government under which this paper was written assumes no liability or responsibility for the contents of this paper or the use of this paper, nor is it endorsing any manufacturers, products, or services cited herein and any trade name that may appear in the paper has been included only because it is essential to the contents of the paper.

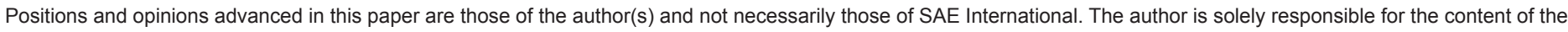
paper. 